OPEN ACCESS

Edited by:

Udo Kraushaar,

Natural and Medical Sciences

Institute, Germany

Reviewed by:

Bruce C. Wheeler,

University of Florida, United States

Michael Thomas Lippert,

Leibniz Institute for Neurobiology (LG),

Germany

*Correspondence:

Valentina Carabelli

valentina.carabelli@unito.it

Specialty section: This article was submitted to

Neural Technology,

a section of the journal

Frontiers in Neuroscience

Received: 10 January 2019

Accepted: 11 March 2019

Published: 09 April 2019

Citation:

Tomagra G, Picollo F, Battiato A

Picconi B, De Marchis S,

Pasquarelli A, Olivero P, Marcantoni A,

Calabresi $P$, Carbone $E$ and

Carabelli V (2019) Quantal Release

of Dopamine and Action Potential

Firing Detected in Midbrain Neurons

by Multifunctional Diamond-Based

Microarrays. Front. Neurosci. 13:288.

doi: 10.3389/fnins.2019.00288

\section{Quantal Release of Dopamine and Action Potential Firing Detected in Midbrain Neurons by Multifunctional Diamond-Based Microarrays}

\author{
Giulia Tomagra ${ }^{1}$, Federico Picollo 2,3 , Alfio Battiato ${ }^{3}$, Barbara Picconi 4,5 , \\ Silvia De Marchis ${ }^{6}$, Alberto Pasquarelli ${ }^{7}$, Paolo Olivero ${ }^{2,3}$, Andrea Marcantoni', \\ Paolo Calabresi ${ }^{8}$, Emilio Carbone ${ }^{1}$ and Valentina Carabelli ${ }^{1 *}$
}

'Department of Drug and Science Technology and "NIS" Inter-departmental Centre, University of Torino, Turin, Italy, ${ }^{2}$ Department of Physics and "NIS" Inter-departmental Centre, University of Torino, Turin, Italy, ${ }^{3}$ Istituto Nazionale di Fisica Nucleare - Sezione di Torino, Turin, Italy, ${ }^{4}$ Experimental Neurophysiology Laboratory, IRCCS San Raffaele Pisana, University San Raffaele, Rome, Italy, ${ }^{5}$ University San Raffaele, Rome, Italy, ${ }^{6}$ Department of Life Sciences and Systems Biology and "NICO" Neuroscience Institute Cavalieri Ottolenghi, University of Torino, Turin, Italy, ${ }^{7}$ Institute of Electron Devices and Circuits, University of Ulm, Ulm, Germany, ${ }^{8}$ Neurological Clinic, Department of Medicine, Hospital Santa Maria della Misericordia, University of Perugia, Perugia, Italy

Micro-Graphitic Single Crystal Diamond Multi Electrode Arrays ( $\mu$ G-SCD-MEAs) have so far been used as amperometric sensors to detect catecholamines from chromaffin cells and adrenal gland slices. Besides having time resolution and sensitivity that are comparable with carbon fiber electrodes, that represent the gold standard for amperometry, $\mu \mathrm{G}$-SCD-MEAs also have the advantages of simultaneous multisite detection, high biocompatibility and implementation of amperometric/potentiometric protocols, aimed at monitoring exocytotic events and neuronal excitability. In order to adapt diamond technology to record neuronal activity, the $\mu \mathrm{G}-\mathrm{SCD}-\mathrm{MEAs}$ in this work have been interfaced with cultured midbrain neurons to detect electrical activity as well as quantal release of dopamine (DA). $\mu \mathrm{G}$-SCD-MEAs are based on graphitic sensing electrodes that are embedded into the diamond matrix and are fabricated using MeV ion beam lithography. Two geometries have been adopted, with $4 \times 4$ and $8 \times 8$ microelectrodes (20 $\mu \mathrm{m} \times 3.5 \mu \mathrm{m}$ exposed area, $200 \mu \mathrm{m}$ spacing). In the amperometric configuration, the $4 \times 4 \mu \mathrm{G}$-SCD-MEAs resolved quantal exocytosis from midbrain dopaminergic neurons. $\mathrm{KCl}$-stimulated DA release occurred as amperometric spikes of $15 \mathrm{pA}$ amplitude and $0.5 \mathrm{~ms}$ half-width, at a mean frequency of $0.4 \mathrm{~Hz}$. When used as potentiometric multiarrays, the $8 \times 8 \mu \mathrm{G}$-SCD-MEAs detected the spontaneous firing activity of midbrain neurons. Extracellularly recorded action potentials (APs) had mean amplitude of $\sim-50 \mu \mathrm{V}$ and occurred at a mean firing frequency of $0.7 \mathrm{~Hz}$ in $67 \%$ of neurons, while the remaining fired at $6.8 \mathrm{~Hz}$. Comparable findings were observed using conventional MEAs ( 0.9 and $6.4 \mathrm{~Hz}$, respectively). To test the reliability of potentiometric recordings with $\mu \mathrm{G}$-SCD-MEAs, the $\mathrm{D}_{2}$-autoreceptor modulation of firing was investigated by applying levodopa (L-DOPA, $20 \mu \mathrm{M}$ ), and comparing $\mu \mathrm{G}$-SCDMEAs, conventional MEAs and current-clamp recordings. In all cases, L-DOPA reduced 
the spontaneous spiking activity in most neurons by $70 \%$, while the $D_{2}$-antagonist sulpiride reversed this effect. Cell firing inhibition was generally associated with increased APs amplitude. A minority of neurons was either insensitive to, or potentiated by L-DOPA, suggesting that AP recordings originate from different midbrain neuronal subpopulations and reveal different modulatory pathways. Our data demonstrate, for the first time, that $\mu \mathrm{G}-\mathrm{SCD}-\mathrm{MEAs}$ are multi-functional biosensors suitable to resolve real-time DA release and AP firing in in vitro neuronal networks.

Keywords: diamond microelectrode arrays, midbrain neurons, quantal release, amperometric detection, spontaneous firing

\section{MATERIALS AND METHODS}

\section{$\mu$ G-SCD-MEA Fabrication}

The employed substrates consisted of chemical vapor deposited single crystal diamonds produced by ElementSix ${ }^{\mathrm{TM}}$ (Didcot, United Kingdom), with concentrations of substitutional nitrogen and boron impurities of 1 and $0.05 \mathrm{ppm}$, respectively. The crystals were cut along the (100) plane and the larger faces were polished.

The implantation process was performed at the AN2000 accelerator of the Laboratories of Legnaro of the Italian National Institute of Nuclear Physics (INFN), by employing a collimated $1.3 \mathrm{MeV} \mathrm{He}{ }^{+}$beam delivered on a $5 \mathrm{~mm} \times 5 \mathrm{~mm}$ spot (Picollo et al., 2015a,b). The collimator was microfabricated by means of laser ablation of a $100 \mu \mathrm{m}$ thick brass film (Kirana-laser, Rovereto, Italy). The implantation fluence $\left(F=1 \times 10^{17} \mathrm{~cm}^{-2}\right)$ was chosen to overcome the graphitization threshold $\left(5 \times 10^{22}\right.$ vac $\mathrm{cm}^{-3}-9 \times 10^{22} \mathrm{vac} \mathrm{cm}^{-3}$ ) (Gippius et al., 1999; Khmelnitsky et al., 2015; Battiato et al., 2016) thus determining the full amorphization of a $\sim 250 \mathrm{~nm}$ thick and $\sim 2.3 \mu \mathrm{m}$ deep layer below the sample surface. Subsequently, a thermal treatment at $950^{\circ} \mathrm{C}$ for $2 \mathrm{~h}$ in high vacuum $\left(10^{-6} \mathrm{mbar}\right)$ was performed in order to promote the complete graphitization of the modified regions (Hoffman et al., 1996; Hickey et al., 2009; Picollo et al., 2012). A preliminary electrical characterization of the device was then performed as previously described (Picollo et al., 2016a).

\section{Ion-Induced Damage Simulation}

The ion-induced damage density profiles were obtained using a numerical simulation performed with the "Stopping and Range of Ion in Matter" SRIM-2013.00 Monte Carlo code (Ziegler et al., 2010) in "Detailed calculation with full damage cascades" mode, by setting a displacement energy value of $50 \mathrm{eV}$ (Wu and Fahy, 1994). The output of the simulation process (i.e., the number of vacancies created per unit of depth and ion, in \#vac \#ions ${ }^{-1}$ $\mu \mathrm{m}^{-1}$ units) was then multiplied by the ion fluence, assuming the absence of non-linear effects such as damage saturation or formation of defect complexes.

\section{Cell Cultures}

The methods for the primary culture of mesencephalic dopamine neurons from substantia nigra (SN) was adapted from Pruszak et al. (2009). The ventral mesencephalon area was dissected from embryonic (E15) C57BL6 TH-GFP mice (Sawamoto et al., 2001; Matsushita et al., 2002). TH-GFP mice were kept heterozygous via breeding TH-GFP mice with C57BL/6J mice. All animals were housed under a 12-h light/dark cycle in an environmentally controlled room with food and water ad libitum. All experiments were conducted in accordance with the European Community's Council Directive 2010/63/UE and approved by the Italian Ministry of Health and the Local Organism responsible for animal welfare at the University of Turin (Authorization DGSAF 0011710-P-26/07/2017).

HBSS (Hank's balanced salt solution, without $\mathrm{CaCl}_{2}$ and $\mathrm{MgCl}_{2}$ ), enriched with $0.18 \%$ glucose, $1 \% \mathrm{BSA}, 60 \%$ papain (Wortington, Lakewood, NJ, United States), 20\% Dnase (SigmaAldrich) was stored at $4^{\circ} \mathrm{C}$ and used as digestion buffer. Neurons were plated at final densities of 600 cells $\mathrm{mm}^{-2}$ on petri dishes, or 2000 cells $\mathrm{mm}^{-2}$ on conventional MEAs or $\mu \mathrm{G}-\mathrm{SCD}$ MEAs. Cultured neurons were used at 7 DIV for current-clamp experiments and at 14 DIV with MEAs or $\mu$ G-SCD-MEAs. Petri dishes, as well as MEAs and $\mu \mathrm{G}$-SCD-MEAs were coated with poly-L-Lysine $\left(0.1 \mathrm{mg} \mathrm{ml}^{-1}\right)$ as substrate adhesion. Cells were incubated at $37^{\circ} \mathrm{C}$ in a $5 \% \mathrm{CO}_{2}$ atmosphere, with Neurobasal Medium containing $1 \%$ pen-strep, $1 \%$ ultra-glutamine, $2 \%$ B- 27 and $2.5 \%$ FBSd; $\mathrm{pH} 7.4$.

\section{Solutions}

For current-clamp experiments the intracellular solution contained (mM): 135 gluconic acid (potassium salt: K-gluconate), $5 \mathrm{NaCl}, 2 \mathrm{MgCl}_{2}, 10$ HEPES, 0.5 EGTA, 2 ATP-Tris and 0.4 TrisGTP. The extracellular solution (Tyrode's solution) contained (mM): $130 \mathrm{NaCl}, 4 \mathrm{KCl}, 2 \mathrm{CaCl}_{2}, 2 \mathrm{MgCl}_{2}, 10$ glucose and 10 HEPES; pH 7.4.

For amperometric recordings, exocytosis was stimulated by means of a KCl-enriched solution, containing (mM): $100 \mathrm{NaCl}$, $2 \mathrm{MgCl}_{2}, 10$ glucose, $10 \mathrm{HEPES}, 10 \mathrm{CaCl}_{2}$, and $30 \mathrm{KCl}$ (pH 7.4).

Potentiometric recordings with MEAs and $\mu \mathrm{G}-\mathrm{SCD}-\mathrm{MEAs}$ were performed while keeping the cells under a controlled $\mathrm{CO}_{2}-$ enriched atmosphere and stable temperature conditions.

\section{Amperometric Recordings}

Amperometric recordings were performed by means of $\mu \mathrm{G}-$ SCD-MEAs $(4 \times 4$ channels geometry $)$ and dedicated electronics, which were designed at the Institute of Electron Devices and Circuits (Ulm University). The whole electronic chain was inserted into a Faraday cage to minimize noise. The chip carrier was directly plugged-in to the front-end electronics connected to a data acquisition unit (National Instruments USB-6216). The 
circuit was grounded by means of a reference $\mathrm{Ag} / \mathrm{AgCl}$ electrode, which was immersed in the extracellular solution. Amperometry was performed by holding the 16 electrodes at a constant potential of $+0.65 \mathrm{~V}$ relative to the $\mathrm{Ag}$ - $\mathrm{AgCl}$ reference electrode.

The acquisition electronics consisted of low-noise transimpedance amplifiers with an input bias current of $1 \mathrm{pA}$ and a gain, set by feedback-resistors, of $100 \mathrm{M} \Omega$. The amplified signals were filtered at $4 \mathrm{kHz}$ with $4^{\text {th }}$ order Bessel low-pass filters and were subsequently acquired at a sampling rate of $25 \mathrm{kHz}$ per channel. The National Instruments DAQ interface was connected to a computer via a high-speed USB. We used data acquisition control software that was developed in LabView. The noise level was evaluated in spike-free trace segments and then averaged over the 16 electrodes, leading to a mean amplitude of $5.5 \pm 0.7 \mathrm{pA}$, with a mean signal-to-noise ratio $(\mathrm{S} / \mathrm{N})$ of $\sim 3$. Spike analysis was performed using "Quanta Analysis" routine (Mosharov and Sulzer, 2005) in Igor pro 5.00 data analysis software by waveMetrics. No change in current output was observed when electrode polarization was lowered below $50 \mathrm{mV}$.

\section{Potentiometric Recordings Using $\mu$ G-SCD-MEAs and MEAs}

Potentiometric recordings were performed while the cells were kept in their culture medium. Recordings took place inside a dedicated incubator, at a controlled temperature and $5 \% \mathrm{CO}_{2}$ atmosphere. A MCS MEA 1060-Inv-BC amplifier from Multi Channel Systems (Reutlingen, Germany) was used as the readout unit for both with $\mu$ G-SCD-MEAs $(8 \times 8$ geometry $)$ and conventional MEAs (60MEA200/300iR-Ti).

Data acquisition was controlled using MC_Rack software. The threshold for spike detection was set at $-30 \mu \mathrm{V}$ and the sampling frequency at $10 \mathrm{kHz}$. Data were then analyzed using Clampfit software (Molecular Devices, Silicon Valley, CA, United States).

\section{Current Clamp Recordings}

Patch-clamp experiments were performed using Pclamp software (Molecular Devices, Silicon Valley, CA, United States). All experiments were performed at a temperature of $22-24^{\circ} \mathrm{C}$. Data analysis was performed using Clampfit software.

\section{Fluorescence Images}

Images were acquired using a Zeiss microscope primovert 40x (Carl Zeiss, LLC United States). In the fluorescence configuration, samples were excited with radiation in the visible spectrum at a characteristic wavelength $\lambda_{\mathrm{ex}}=470 \mathrm{~nm}$, and the emission wavelength was $\lambda_{\mathrm{em}}=505 \mathrm{~nm}$, which is typical of GFP staining.

\section{Statistical Analysis}

Data are given as mean \pm SEM, for $n$ number of cells, except where otherwise specified. Statistical significance was estimated using unpaired Student's $t$-tests. Data were considered statistically significant when $p \leq 0.05$. Statistical analysis was performed with Origin 8.5 software (OriginLab Corporation, Northampton, MA, United States).

\section{INTRODUCTION}

Dopamine (DA) plays fundamental roles in a variety of neurophysiological functions and neurological diseases. Dopaminergic microcircuits are involved in movement, reward, memory and cognition (Waelti et al., 2001), while the degeneration of the nigrostriatal pathway in Parkinson's disease (PD) impairs control and planning of movement, causing tremors and postural instability.

Fluctuations of DA concentration occur on the seconds to subseconds time scale, thus making them suitable for study with carbon fiber electrodes (CFEs) and fast-scan cyclic voltammetry (Hafizi et al., 1990; Kawagoe and Wightman, 1994; Heien and Wightman, 2006; Patel and Rice, 2013). However, in vivo DA electrochemical detection is hampered by electrode fouling, which is caused by accumulation of oxidized products and by interference of ascorbic and uric acid, ultimately limiting electrode sensitivity and selectivity (Suzuki et al., 2007).

Since the early investigation of synaptic dysfunction is a target when attempting to understand the molecular mechanisms that lead to neurodegenerative processes, the development of mutifunctional sensing tools for simultaneous monitoring neurotransmitter release and electrical activity are extremely relevant for addressing key aspects of neurotransmission in the early stages of neurodegenerative diseases (Suzuki et al., 2013; Schirinzi et al., 2016; Castagnola et al., 2018; Ghiglieri et al., 2018; Picconi et al., 2018).

In this regard, conventional multielectrode arrays (MEAs) have been employed to investigate the firing properties in $\mathrm{SN}$ pars compacta slices (Berretta et al., 2010), while amperometric detection of DA release from cultured neurons, was initially performed using CFEs (Pothos et al., 1998; Pothos, 2002; Staal et al., 2004; Mosharov and Sulzer, 2005). A range of different amperometric microarrays to detect DA release from PC12 cells (Chen et al., 1994; Lin et al., 2012; Trouillon and Ewing, 2014), striatal slices (Suzuki et al., 2013) and from isolated dopaminergic somas from the pond snail Lymnaea stagnalis have been designed (Patel et al., 2013). Dopamine release from striatal slices has been detected by carbon nanotube multi electrode arrays and the same device could successfully detect APs and field postsynaptic potentials from cultured hippocampal neurons and slices (Suzuki et al., 2013). In spite of this, no data concerning the detection of quantal release and electrical activity from the same cultured neurons using the same multiarray prototypes have been reported, to the best of our knowledge. Micro-graphitic single-crystal diamond multielectrode arrays ( $\mu \mathrm{G}-\mathrm{SCD}-\mathrm{MEAs}$ ) are a powerful sensor for investigating neurosecretion in living cells (Picollo et al., 2013, 2015b). Previous findings have demonstrated their ability to monitor spontaneous and evoked quantal catecholamine release from cultured mouse and bovine adrenal chromaffin cells (Picollo et al., 2016b) as well as from fresh mouse adrenal slices (Picollo et al., 2016a; Carabelli et al., 2017). Besides providing simultaneous recordings from a variety cells, which have been plated and cultured on the planar array for a number of days, $\mu \mathrm{G}$-SCD-MEAs possess high-time resolution and sensitivity for the detection of amperometric events with different shape, such as the small amplitude, or previously 
identified "stand-alone-foot" events (Picollo et al., 2016a). Taking advantage of diamond biocompatibility (Bonnauron et al., 2008; Nistor et al., 2015; Piret et al., 2015; Alcaide et al., 2016), we have succeeded in culturing primary midbrain neurons on $\mu \mathrm{G}$ SCD-MEAs. In the present work, we have provided the first evidence that $\mu \mathrm{G}-\mathrm{SCD}-\mathrm{MEAs}$ can detect the quantal exocytosis of neuronal synaptic vesicles as well as spontaneous neuronal firing activity.

\section{RESULTS}

\section{Fabrication of $\mu$ G-SCD-MEAs}

The electrochemical sensors that have been used in the present work consist of multi electrode arrays with either 16 or 60 graphitic electrodes that have been embedded into an artificial single-crystal diamond substrate. The two devices combine the properties of diamond, including: (1) biocompatibility, guaranteeing the plating and maintenance of primary cultures for weeks (Tang et al., 1995; Nistor et al., 2015); (2) chemical inertness, which prevents modifications to the employed solutions; and (3) wide optical transparency.

Conventional fabrication schemes cannot be used for the assembly of these sensors due to the extreme chemical/physical characteristics of diamond, meaning that an advanced $\mathrm{MeV}$ ion-beam-implantation-based process was used (Olivero et al., 2010; Picollo et al., 2015b). This fabrication technique allows the selective phase transition from the diamond to graphite to be promoted by taking advantage of the metastable nature of the substrate. Indeed, if the density of ion beam-induced defects (commonly parametrized in terms of vacancy density) overcomes a critical threshold, the graphitization of the damaged region is obtained upon high-temperature thermal treatment. Moreover, the fact that the defects created by irradiation with $\mathrm{MeV}$ ions follow a typical distribution, which is characterized by the so-called "Bragg peak" and the ion end of range (Figure 1A), means the position of the graphitic electrodes can be modulated along the substrate depth, thus guaranteeing intrinsic electrical passivation due to the presence of the diamond cap layer. Only the electrodes end-points emerge to the surface, thus allowing the interfacing with the front-end electronic in the peripheral region of the sensor and the cells coupling in the central region.

Figures 1B,C shows the sensor and the magnification of the graphitic electrodes, which were arranged in a $4 \times 4$ matrix, while Figures 1D,E show analogous representations for the device with a $8 \times 8$ matrix of electrodes (without the four electrodes on the corners). In both cases, active areas were regularly spaced with a $\sim 200 \mu \mathrm{m}$ step.

\section{Real-Time Detection of Quantal DA Release From Midbrain Neurons Using $\mu$ G-SCD-MEAs}

DA release from cultured midbrain neurons can either occur at the somato-dendritic or the axon-terminal level (Rice and Patel, 2015). In this work, we have cultured midbrain neurons for $20 \mathrm{DIV}$ on $\mu \mathrm{G}$-SCD-MEAs and found that quantal exocytotic events can be detected after 10 DIV. Under our experimental conditions, the density of cell plating on the

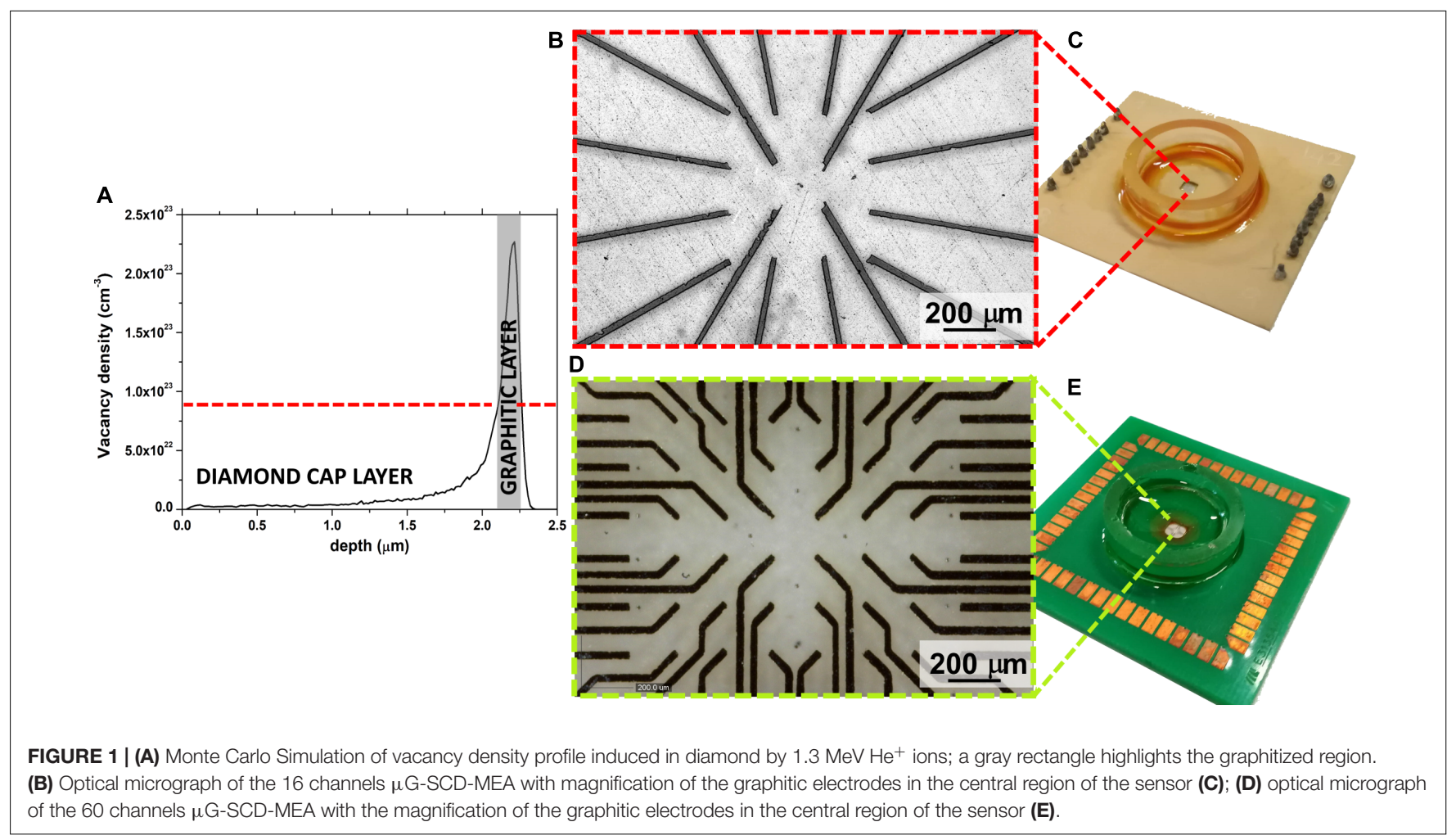


multiarray (see section "Materials and Methods"), allowed us to reveal amperometric signals from approximately 25$30 \%$ of the electrodes. Unstimulated (i.e., spontaneous) release was barely detectable (5\% of trials) and occurred at low frequency $(0.11 \pm 0.07 \mathrm{~Hz})$ in $2 \mathrm{mM} \mathrm{CaCl}_{2}$ (Figure 2A). Amperometric spikes were characterized by a mean maximum current amplitude $\left(\mathrm{I}_{\max }\right)$ of $13.2 \pm 1.0 \mathrm{pA}$ and a half-time width ( $t_{\text {half }}$ ) of $0.57 \pm 0.03 \mathrm{~ms}(n=5)$. Stimulation with $30 \mathrm{mM} \mathrm{KCl}$ (Figures 2A-C) increased the release frequency to $0.40 \pm 0.03 \mathrm{~Hz}$. However, spike parameters were unaffected: $\mathrm{I}_{\max }$ was $18.5 \pm 1.1 \mathrm{pA}$ and $\mathrm{t}_{\text {half }}$ was $0.52 \pm 0.01 \mathrm{~ms}(n=13$ cells, from $4 \mu \mathrm{G}$-SCD-MEAs). On the other hand, $200 \mu \mathrm{M} \mathrm{CdCl}$ suppressed $\mathrm{Ca}^{2+}$-dependent exocytosis through voltage-gated $\mathrm{Ca}^{2+}$ channels, as shown in Figure 2A. No events were detected when the recording electrodes were polarized to $0 \mathrm{mV}$ to nullify dopamine detection (bottom trace). Representative recordings of simultaneous acquisition from five different electrodes of the same $\mu$ G-SCD-MEA are shown in Figure 2B: multiple events, such as the one visible in the first trace, were discarded from the analysis. Some representative spikes that were recorded in the presence of $\mathrm{KCl}$ are shown at a more expanded time scale in Figure 2C.

\section{Detection of Spontaneous AP Firing From Cultured Midbrain Neurons}

After assessing the sensitivity of $\mu$ G-SCD-MEAs to reveal quantal DA release in dopaminergic neurons, we tested if these sensors

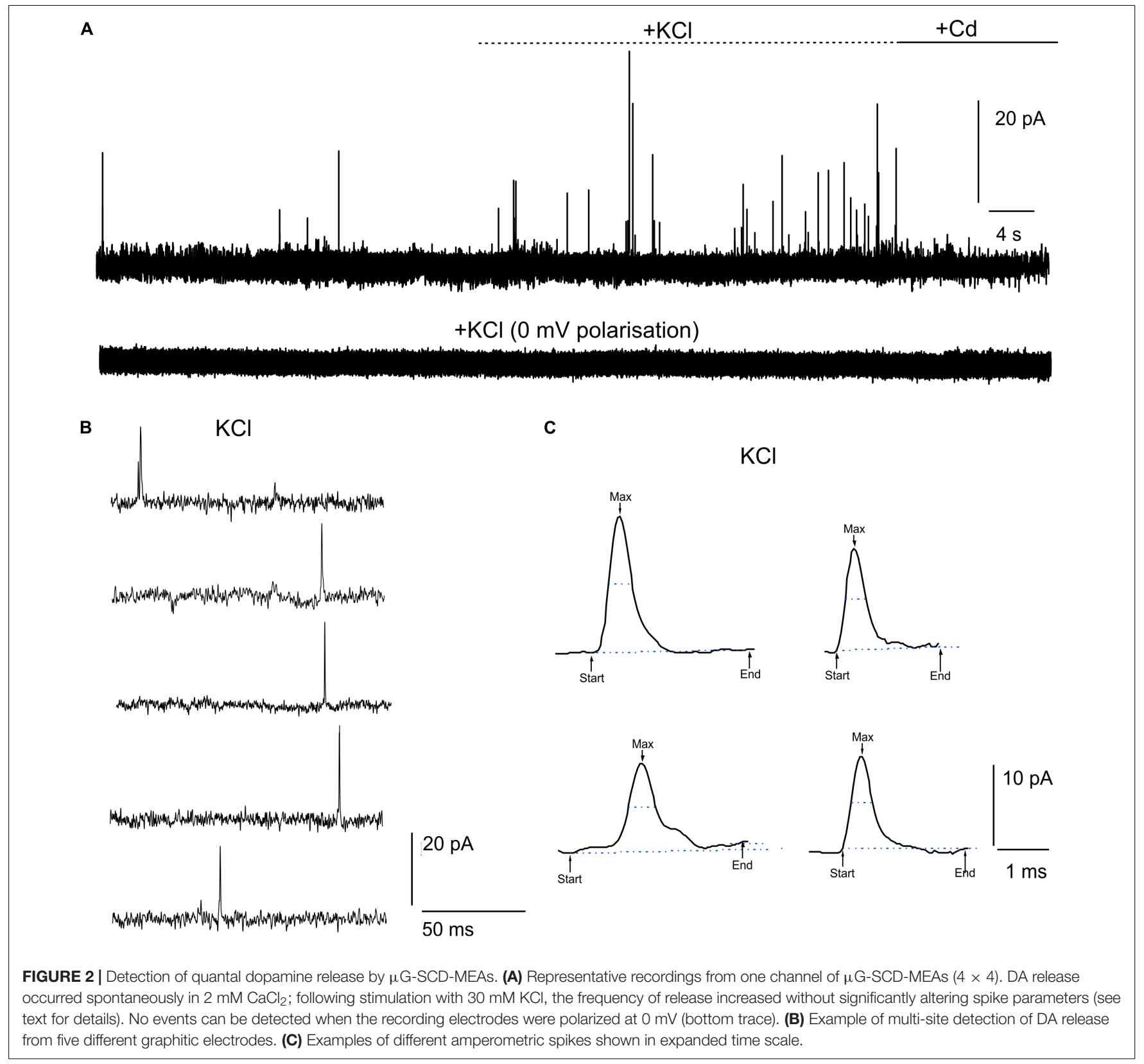


were able to measure the electrical activity of cultured midbrain neurons. For this purpose, $\mu \mathrm{G}$-SCD-MEAs were patterned with a higher electrode number $(8 \times 8$ array $)$ than to those used for amperometry $(4 \times 4$ array). Recordings were performed in parallel using $\mu \mathrm{G}-\mathrm{SCD}-\mathrm{MEAs}$ and conventional MEAs [Multi Channel Systems (MCS)], for a more rigorous interpretation of acquired data. As has already been observed in cultured hippocampal neurons (Gavello et al., 2012, 2018; Allio et al., 2015) and other brain regions (Martinoia et al., 2005), mesencephalic DA neurons start generating spontaneous APs after 7 DIV (Henderson et al., 2016), while network functionality was wellresolved at 14 DIV.

Representative recordings of spontaneously firing midbrain neurons, measured using $\mu \mathrm{G}-\mathrm{SCD}-\mathrm{MEAs}$ and conventional MEAs, are shown in Figure 3A. This spontaneous spiking activity occurred under physiological conditions $\left(2 \mathrm{mM} \mathrm{Ca}^{2+}\right)$ and was suppressed by blocking the firing during the exogenous application of $300 \mathrm{nM}$ TTX (data not shown). Unlike amperometric spikes, which exibit monopolar waveforms, single APs (Figure 3B) were characterized by a fast downward deflection (negative peak), which corresponds to the AP rising phase, followed by an upward deflection (positive antipeak), which is associated to the AP repolarising phase (Fromherz, 1999; Marcantoni et al., 2007). The mean amplitude of the negative peaks recorded by $\mu \mathrm{G}-\mathrm{SCD}-\mathrm{MEAs}(n=10)$ was $-50.2 \pm 3.6 \mu \mathrm{V}$, with $\mathrm{S} / \mathrm{N}$ of $\sim 4$, while the mean signal amplitude was equal to $-54.0 \pm 4.7 \mu \mathrm{V}$, with $\mathrm{S} / \mathrm{N}$ of $\sim 5$, for conventional MEAs $(n=10)$. The amplitude of the positive antipeak, when detectable, was approximately $30 \%$ of the negative peak amplitude. For instance, for the channels indicated by the asterisks in Figure 3A, the mean positive antipeak amplitudes was $25.4 \pm 0.4$ and $26.0 \pm 0.4 \mu \mathrm{V}$ (with $\mu$ G-SCD-MEAs and MEAs, respectively), while the mean peak amplitude was $-60.1 \pm 0.6$ and $-67.1 \pm 0.5 \mu \mathrm{V}$ (with $\mu \mathrm{G}$ SCD-MEAs and MEAs, respectively). Since the positive antipeak was not detectable in all neurons, we limited our analysis to the negative peak, in good agreement with our previous observations (Vandael et al., 2010).

Firing frequencies were comprised within 0.1 and $15 \mathrm{~Hz}$ (Figure 3C), which is consistent with the presence of distinct neuronal populations within the network (Berretta et al., 2010; Ramayya et al., 2014). Most neurons (67\%) were spontaneously active, fired with a basal frequency which not exceeded $4 \mathrm{~Hz}$ and had a mean firing frequency of $0.66 \pm 0.14$ or $0.90 \pm 0.10 \mathrm{~Hz}$, when measured with $\mu \mathrm{G}$-SCD-MEAs and conventional MEAs $(p>0.1)$, respectively. The remaining neurons had a much higher basal firing frequency, ranging between 4 and $11 \mathrm{~Hz}$ and characterized by mean values of $6.8 \pm 1.4$ and $6.4 \pm 0.5 \mathrm{~Hz}$, when measured with $\mu \mathrm{G}$-SCD-MEAs

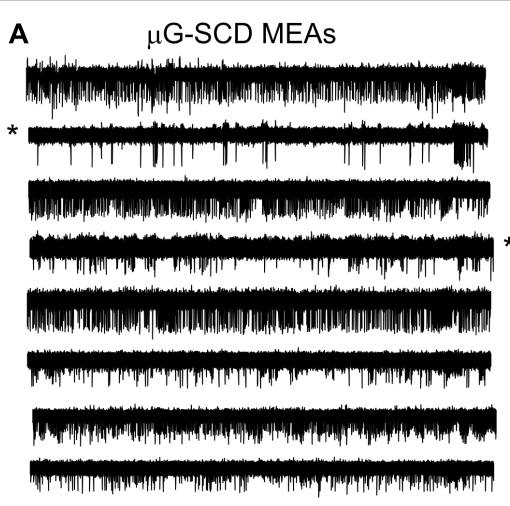

A

C

firing frequency
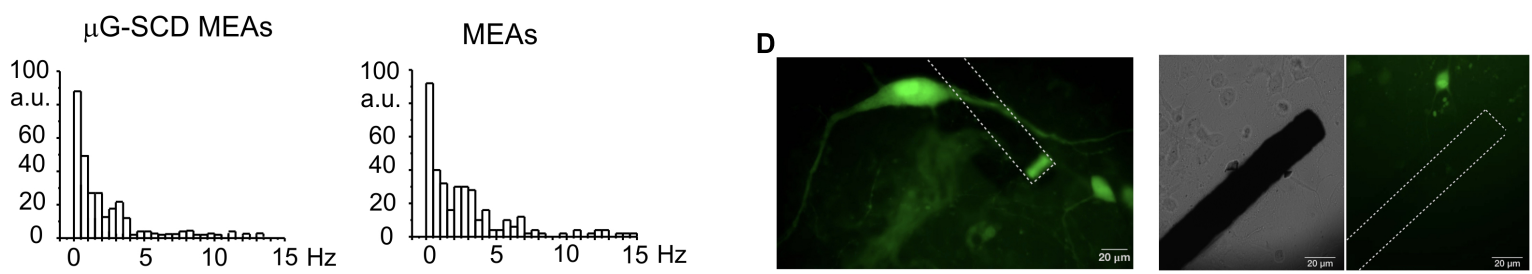

FIGURE 3 | Potentiometric recordings from $\mu \mathrm{G}$-SCD-MEAs and MEAs. (A) Representative spontaneous firing activity of cultured midbrain neurons detected using $\mu$ G-SCD-MEAs (left) and MEAs (right). (B) Top: representative extracellularly detected APs shown on an expanded time scale for both devices. The red trace is the averaged signal. Bottom: the bar histogram represents the mean peak amplitude (negative deflection) and antipeak amplitude (positive deflection) of the extracellularly recorded APs. Data refer to the traces indicated by the asterisks in (A). (C) Firing frequency distribution for $\mu$ G-SCD-MEAs and MEAs. Number of data are reported as percentages, indicated as arbitrary units (a.u.). (D) GFP-TH positive staining neurons cultured on $\mu$ G-SCD-MEA (left). Dashed lines represent the buried graphitic channels inside the diamond bulk. The graphitic emerging (sensing) electrode appears as rectangular shaped. Middle, right: a single graphitic channel on an expanded scale in the proximity of a dopaminergic neuron. The same image is shown in transmitted light (middle) and in fluorescence (right). 
and MEAs $(p>0.1)$, respectively. This heterogeneity of responses can, most likely, be ascribed to the presence of distinct neuronal populations such as DA neurons from SN, GABAergic and DA neurons from the nearby ventral tegmental area (Berretta et al., 2010; Cucchiaroni et al., 2011). Optical images of GFP-TH ${ }^{+}$neurons that were cultured on $\mu \mathrm{G}$-SCD-MEAs are provided in Figure 3D.

Despite the above-mentioned heterogeneity, these recordings are the first experimental evidence that $\mu \mathrm{G}$-SCD-MEAs are suitable for potentiometric recordings from primary cultures of brain neurons.

\section{$D_{2}$-Autoreceptor Induced Inhibition of Repetitive Firing in Current-Clamp Recordings}

The firing of nigral dopaminergic neurons is down-regulated by $\mathrm{DA}$ release through a $\mathrm{D}_{2}$-autoreceptor mediated pathway (Aghajanian and Bunney, 1977; Mercuri et al., 1990). Since this down-regulatory pathway has been observed in midbrain slices and we were recording from primary cultured midbrain dissociated neurons (Lacey et al., 1987; Guatteo et al., 2013), we aimed to identify this inhibitory down-regulation under our experimental conditions first (Bigornia et al., 1990). Preliminary experiments were performed in whole-cell currentclamp configuration, by applying the DA precursor levodopa (L-DOPA) (20 mM). Recordings were selectively performed on 7 DIV dopaminergic neurons that were identified by means of GFP staining (Figure 3D). Although the responses to applied L-DOPA varied, it caused a $70 \pm 4 \%$ reduction of the firing frequency in $80 \%$ of cases $(n=20$ cells, from $1.36 \pm 0.02$ to $0.41 \pm 0.11 \mathrm{~Hz}$; Figures 4A,F). Maximum inhibition occurred within 2-5 min of L-DOPA perfusion, and was reversed some minutes after the application of the $D_{2}$ antagonist sulpiride $(10 \mu \mathrm{M})$. The repetitive firing frequency measured in the presence of the $\mathrm{D}_{2}$ antagonist recovered to $1.2 \pm 0.2 \mathrm{~Hz}$, thus confirming the autocrine inhibition that is induced by released DA (Guatteo et al., 2013). It is worth mentioning that the reduced firing frequency was associated, in $70 \%$ of the cases, to a membrane hyperpolarization of $-7.8 \pm 1.1 \mathrm{mV}$ and by a sharp increase in AP peak amplitude (from $27 \pm 3$ to $35.6 \pm 1.6 \mathrm{mV} ; n=14, p<0.05$; Figures 4C,D). All this was most likely induced by the DAmediated activation of a G-protein-coupled potassium channel

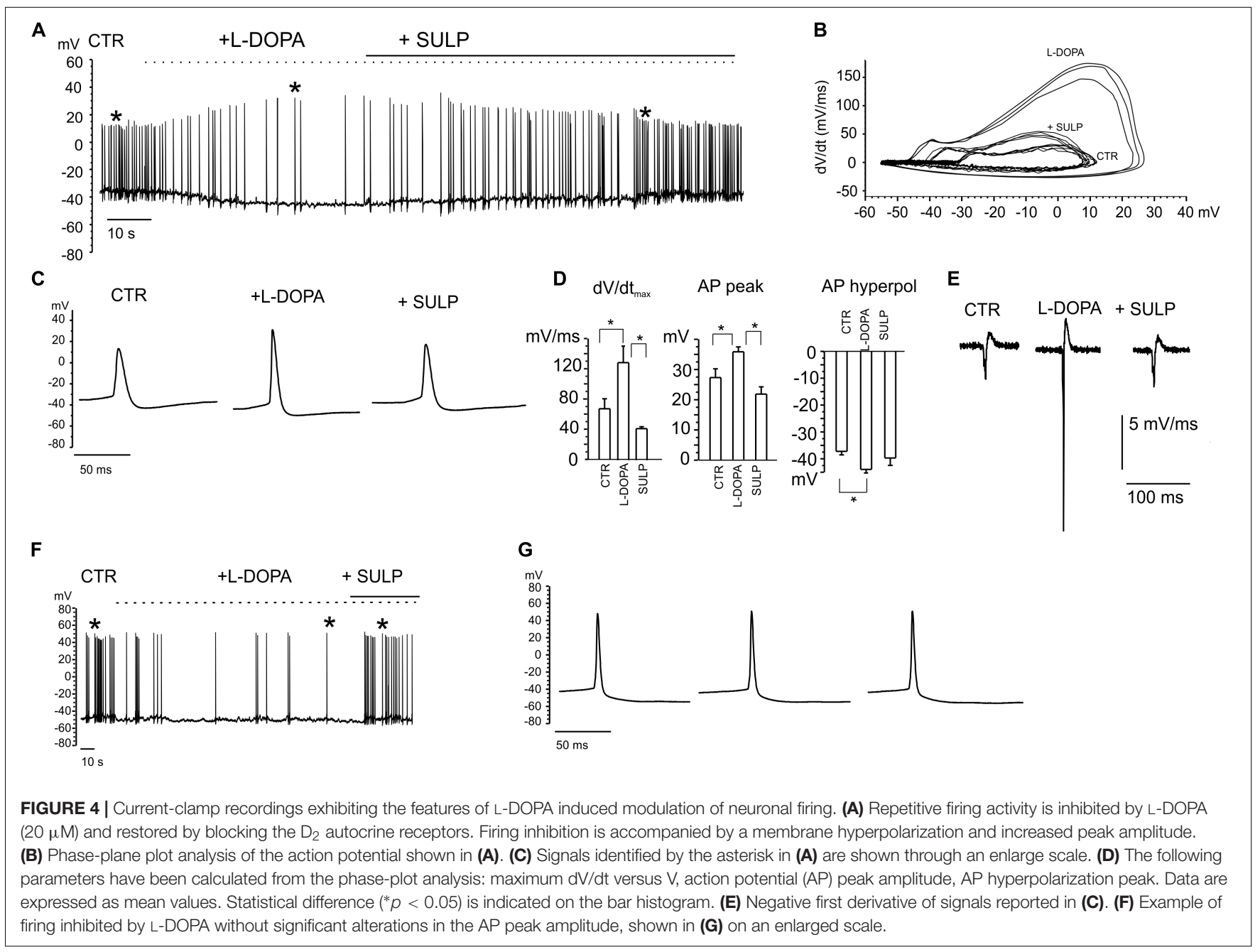


(GIRK) (Lacey et al., 1987). Both effects were reversed after perfusion with sulpiride.

In the remaining $30 \%$ of neurons, the nearly threefold reduction of firing frequency occurred without causing either the significant hyperpolarization of the membrane potential, or alterations in the AP waveform (Figures 4F,G). For this subset of neurons, in some cases sulpiride restored the control firing frequency, even though the recovery was not always complete. This variability reveals the probable existence of distinct modulatory pathways that may originate from different midbrain neuron subpopulations (Dragicevic et al., 2015; Duda et al., 2016).

Phase plane plot analysis was performed in order to gain further insights into the APs properties and their modulation by L-DOPA (Vandael et al., 2012; Marcantoni et al., 2014). By plotting the time derivative of voltage versus voltage $(d V / d t)$, parameters such as the AP threshold can be easily inferred from the voltage value at which $\mathrm{dV} / \mathrm{dt}$ suddenly increases. The phaseplane plots in Figure $4 \mathrm{~B}$ are referred to the same APs that are indicated by the asterisks in Figure 4A. From the plot we

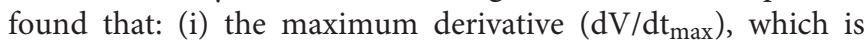
associated with the maximum current density through voltagegated $\mathrm{Na}_{\mathrm{v}}$ channels, was drastically enhanced by L-DOPA (from 67 to $129 \mathrm{mV} \mathrm{ms}^{-1}, p<0.05$, Figure 4D), suggesting a sustained recruitment of $\mathrm{Na}_{\mathrm{v}}$ channels (Guarina et al., 2018); (ii) the AP hyperpolarization peak was significantly augmented by L-DOPA, from from $-37.2 \pm 1.3$ to $-40 \pm 2 \mathrm{mV}$ ( $p<0.05$, Figure 4D); (iii) the AP threshold, measured from the phase-plane plot when an abrupt change in $\mathrm{dV} / \mathrm{dt}$ was observed (at $4.5 \pm 1.2 \mathrm{mV} \mathrm{ms}^{-1}$ for control and $6.4 \pm 0.9 \mathrm{mV} \mathrm{ms}^{-1}$ for L-DOPA-treated neurons), decreased from $-25.3 \pm 1.8$ to $-31.9 \pm 1.8 \mathrm{mV}(p<0.05)$, respectively. This again confirms a potentiated recruitment of $\mathrm{Na}_{\mathrm{V}}$ channels during L-DOPA treatment.

In order to compare the AP waveform recorded intracellularly with those recorded extracellularly, the negative first derivative of AP traces shown in Figure 4C is reported in Figure 4E. They correspond to the AP shape recorded extracellularly by the MEAs (Fromherz et al., 1991) and identified as a biphasic AP waveform in which, similarly to that of Figure 3B, a large negative peak and a small positive antipeak component can be distinguished.

Finally, a range of different effects on neuronal activity were detected in the neurons that were not inhibited by L-DOPA $(20 \%$ of neurons). L-DOPA accelerated repetitive firing by $80 \pm 20 \%$ (17\% of neurons), while it was ineffective in the remaining ones (3\% of neurons).

\section{Heterogeneity of L-DOPA Induced Responses in Cultured Midbrain Neurons Observed Through $\mu$ G-SCD-MEAs and Conventional MEAs}

Potentiometric recordings using $\mu \mathrm{G}-\mathrm{SCD}$-MEAs were performed to simultaneously detect spikes arising from different neuronal populations and to investigate their responses to the applied drugs. With respect to patch-clamp experiments, performed on isolated and young neurons (7 DIV), these trials were designed to provide a rapid screening of the effects of L-DOPA on mature networks (14 DIV). After the firing properties under control conditions were monitored for a couple of minutes, the addition of L-DOPA to the culture medium revealed three different responses, confirming the existence of heterogeneous firing, as measured in SN slices (Berretta et al., 2010). In most cases (70\% of neurons), the firing activity was significantly reduced by L-DOPA and the inhibitory effect required some minutes for completion (Mercuri et al., 1990). As shown in a representative recording using $\mu \mathrm{G}-\mathrm{SCD}-\mathrm{MEAs}$, the firing frequency was reduced by $80 \%$ after $2-3 \mathrm{~min}$, and the extracellular AP peak increased from $-75 \pm 1$ to $-87 \pm 3 \mu \mathrm{V}$, while sulpiride reversed both effects, suggesting that $\mathrm{D}_{2}$ autoreceptors are involved (Figures 5 A,C). On average L-DOPA decreased the spontaneous spiking activity from 1.1 to $0.3 \mathrm{~Hz}$ and increased the negative peak amplitude by $14 \%(n=5 \mu \mathrm{G}-$ SCD-MEAs, $p<0.05$ ), suggesting a prominent recruitment of $\mathrm{Na}_{\mathrm{v}}$ channels following L-DOPA hyperpolarization. In order to validate these experimental findings, we repeated the same experiments using conventional MEAs. Once again, the majority of neurons (64\%), responded to L-DOPA by reducing the mean firing frequency, on average from $1.5 \pm 0.7$ to $0.29 \pm 0.09 \mathrm{~Hz}$ $(p<0.05, n=10$ MEAs; Figure 5B), while sulpiride restored the basal frequency to $1.1 \pm 0.3 \mathrm{~Hz}$ (Figure 5C). In this subset of neurons, firing frequency reduction was also associated to a $20 \%$ increase in the negative peak amplitude, confirming the prominent role that $\mathrm{D}_{2}$-autoreceptors play in L-DOPA induced inhibition.

Nevertheless, a relevant fraction of neurons in the mature networks (30 and 36\%, respectively for $\mu \mathrm{G}$-SCD-MEAs and MEAs) also displayed a significant increase (up to sixfold) in spontaneous frequency and a $30 \%$ reduction in the negative peak amplitude following exposure to L-DOPA. This is in good agreement with the heterogeneity of responses that we observed in dissociated neurons under current-clamp conditions. In the example shown in Figure $\mathbf{6 A}$ for $\mu \mathrm{G}-\mathrm{SCD}-\mathrm{MEAs}$, the negative peak amplitude decreased from $-44.1 \pm 1.2$ to $-34.2 \pm 1.1 \mu \mathrm{V}$, while the firing frequency increased from 0.5 to $2.9 \mathrm{~Hz}$ (Yasumoto et al., 2004). Similarly, the potentiation of firing activity by L-DOPA occurred with a mean threefold increase in firing frequency when using conventional MEAs, and was usually accompanied by a $28 \%$ decrease in the negative peak amplitude (Figure 6B).

L-DOPA reduced the spiking activity without affecting the AP shape in the remaining cases. Examples of this modulation are shown in Figure 6C. The unaltered amplitude of the negative AP peak, that have been revealed by $\mu \mathrm{G}$-SCD-MEAs and conventional MEAs (Figure 6D), confirms the findings obtained under patch-clamp conditions, in which $30 \%$ of neurons displayed a reduced firing frequency without alterations of the AP rising phase.

\section{DISCUSSION}

We have provided the first evidence that $\mu$ G-SCD-MEAs allow long-term neuronal cultures to be performed and that they can 


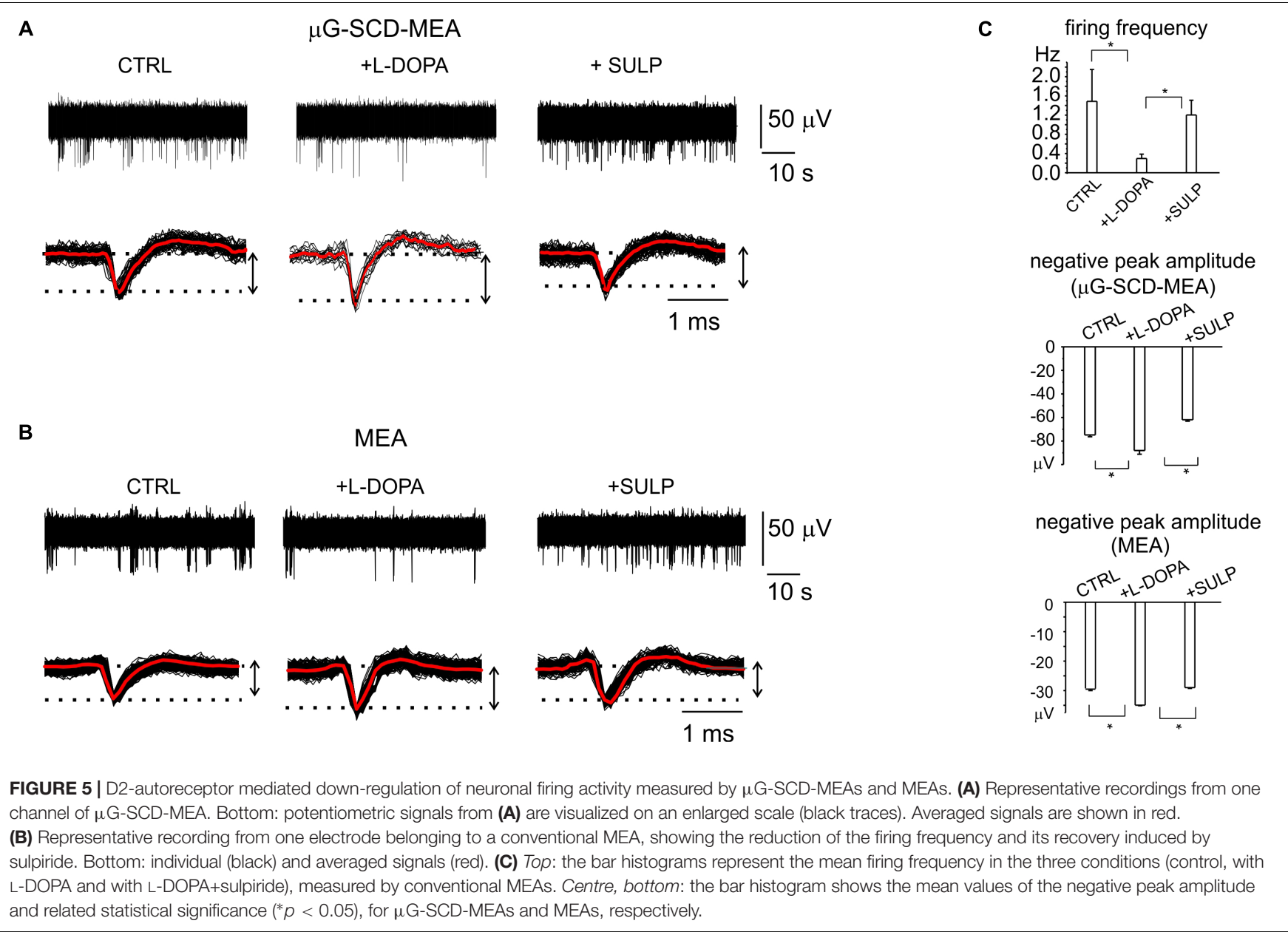

function as sensing devices for recording quantal exocytosis and spontaneous AP firing.

\section{Amperometric Detection of Quantal Dopamine Release}

Amperometric recordings have proved that $\mu \mathrm{G}-\mathrm{SCD}-\mathrm{MEAs}$ are suitable for the real time detection of exocytosis from neuronal networks. Under physiological conditions (2 $\mathrm{mM}$ $\left.\mathrm{Ca}^{2+}\right), \mu \mathrm{G}-\mathrm{SCD}-\mathrm{MEAs}$ can resolve spontaneous secretory events as amperometric spikes of $<20 \mathrm{pA} \mathrm{I}_{\max }$ and mean quantity of charge Q of $0.01 \mathrm{pC}$, which can most likely be associated with the tonic discharge activity of the network (Sulzer et al., 2016). These exocytotic events are significantly smaller than those of released catecholamines from large dense-core vesicles of adrenal chromaffin cells, whose $I_{\max }$ is in the order of 10 s of $\mathrm{pA}$, and $\mathrm{Q}$ is $>1.5 \mathrm{pC}$, as has already been reported using the same $\mu$ G-SCD-MEAs (Picollo et al., 2016b).

When using $\mathrm{KCl}$ as a secretagogue to increase the probability of release from DA neurons, a mean release of $3.7 \times 10^{4}$ DA molecules/spike was found. Comparable neurotransmitter content values $\left(\sim 3 \times 10^{4} \mathrm{DA}\right.$ molecules $)$ were estimated from axonal DA vesicles using CFEs (Sulzer et al., 2016). In other CFE experiments on postnatally derived midbrain neurons, performed at a $100 \mathrm{kHz}$ sampling rate to discriminate between single-spike and flickering events, DA release values were estimated to be around $1 \times 10^{4}$ and $2.4 \times 10^{4} \mathrm{DA}$ molecules, respectively for single-spike and flickering events (Staal et al., 2004). It is worth noting that estimates of quantal size can be affected by the different experimental configurations used, such as detection being performed from the cell apex using CFEs or from the cell bottom using $\mu \mathrm{G}$-SCD-MEAs (Amatore et al., 2007).

\section{Detection of Spontaneous Firing From Cultured Midbrain Neurons}

Besides detecting the quantal release of DA, $\mu$ G-SCD-MEAs can be exploited to measure the electrical activity of cultured midbrain neurons. The $8 \times 8 \mu \mathrm{G}$-SCD-MEAs and the conventional MEAs can reveal APs only after 7 DIV in approximately $30 \%$ of the electrodes, due to the delayed maturation of the network after dissociation. However, the network activity becomes detectable in most (i.e., 70\%) of the electrodes at later stage of maturation (14 DIV). Spontaneous firing at this stage of maturation exhibits great variability of responses, even within the same $\mu \mathrm{G}$-SCD-MEA or conventional MEA. Neuronal firing frequencies were scattered throughout a 
A
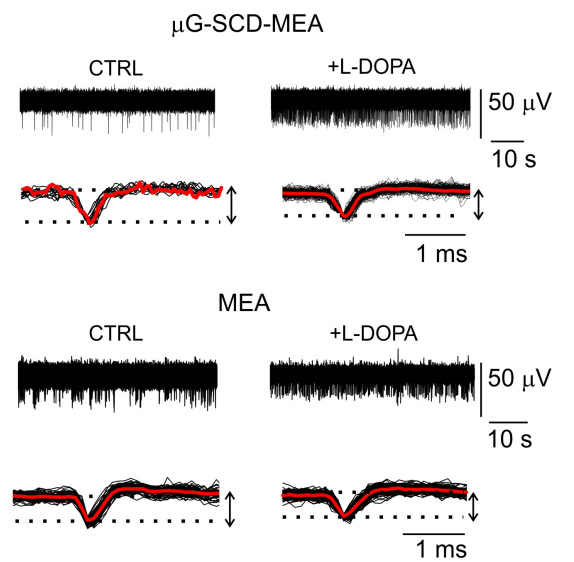

B
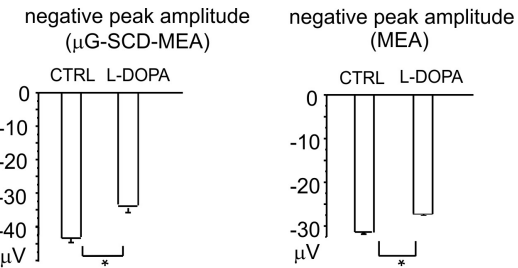
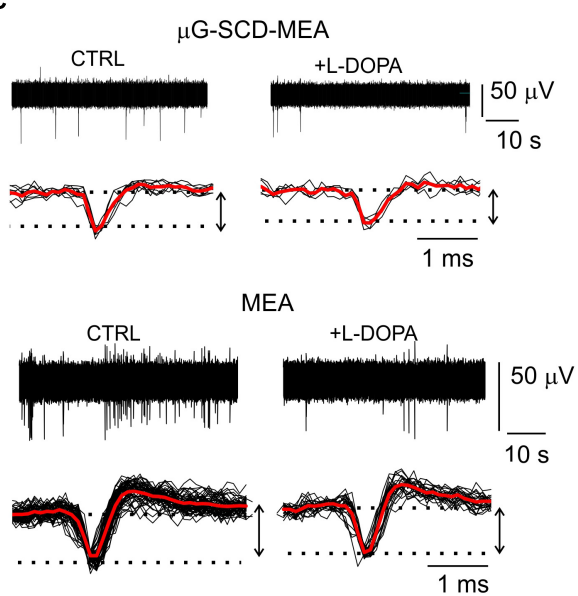

D

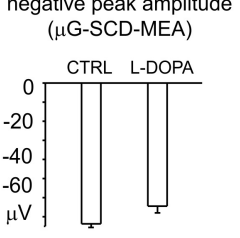

negative peak amplitude (MEA)

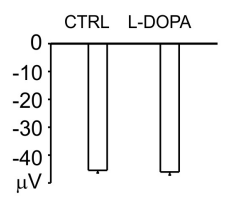

FIGURE 6 | Heterogeneity of L-DOPA-induced responses on midbrain neurons viewed through $\mu$ G-SCD-MEAs and MEAs. (A) Representative recordings of L-DOPA-induced potentiation of neuronal firing, respectively acquired by $\mu$ G-SCD-MEAs (top) and MEAs (bottom). Under each recording, individual (black) and averaged signals (red) are shown on an expanded time scale. (B) L-DOPA induced potentiation is associated to the reduced amplitude of the AP peak, as shown in the bar histograms. (C) L-DOPA reduces the firing frequency without causing any significant alteration in the extracellularly recorded peak amplitude. Significant recordings detected by $\mu$ G-SCD-MEAs (top) and MEAs (bottom). (D) The bar histograms show the mean negative peak amplitude, which is not affected by L-DOPA, for both devices.

range of frequencies varying from 0.1 to $15 \mathrm{~Hz}$ (Figure 3C) for both devices, which is in reasonably good agreement with previous reports of low frequency activity in isolated SN DA neurons (Bean, 2007; Margolis et al., 2010). A broad distribution of firing frequencies has also been observed in SN slices positioned onto conventional MEAs: the majority of neurons ( $\sim 94 \%$ ) exhibit low firing frequencies (i.e., $1-3 \mathrm{~Hz}$ ), whereas the remaining ones fire at higher frequencies $(5-10 \mathrm{~Hz})$ (Berretta et al., 2010). Different firing patterns have also been described for in vivo recordings, where SN DA neurons display both slow single-spike activity $(1-10 \mathrm{~Hz})$, and higher frequency discharges ( 13-20 Hz) (Dragicevic et al., 2015; Hage and Khaliq, 2015). A final consideration concerns the low firing rate $(<1 \mathrm{~Hz})$ that was recorded in the majority of neurons, and the hardly detectable DA release that occurred at $0.1 \mathrm{~Hz}$. Both processes suggest the existence of a tonic discharge activity at rest, partially tuned by $\mathrm{D}_{2}$-autoreceptors (Al-Hasani et al., 2011).

\section{Using $\mu$ G-SCD-MEAs for \\ Pharmacological Studies: The L-DOPA-Induced Down-Modulation of Spontaneous Firing}

The neuronal discharge of SN DA neurons is inhibited by $\mathrm{D}_{2}$ autoreceptors-mediated GIRK activation and is prevented by the
$\mathrm{D}_{2}$-antagonist sulpiride (Mercuri et al., 1990; Dragicevic et al., 2014). To assay the sensitivity of the $\mu$ G-SCD-MEAs, we tested this inhibitory pathway in current-clamped TH-GFP neurons, as well as in mature midbrain DA neurons, cultured for 2 weeks on $\mu \mathrm{G}$-SCD-MEAs (or conventional MEAs). This autocrine inhibition is induced by adding L-DOPA, which is converted to DA and then released from dopaminergic neurons.

As shown, L-DOPA caused a range of effects (Figure 4). In most current-clamped neurons, the response caused a firing frequency reduction together with a slow membrane hyperpolarization and an increased AP amplitude that was reverted by sulpiride. The increased AP amplitude and the rapid increase in the AP rising phase was revealed as an enhanced $d V / d t$ peak amplitude in the phase-plane plot analysis of AP recordings. The same occurrence was detected using both the $\mu$ G-SCD-MEAs and conventional MEAs (Figure 5). Both MEAs revealed the reduced firing frequency and the increased AP rising phase, which were reverted by sulpiride. It is worth noting that, in the case of MEAs, the increased AP rising phase in currentclamp recordings is converted to an increased peak amplitude in the extracellular APs.

From a physiological point of view, both measurements are in excellent agreement and suggest sustained recruitment of $\mathrm{Na}_{\mathrm{V}}$ channels due to the increased cell hyperpolarization induced by GIRK $\mathrm{K}^{+}$channel activation. Sustained cell hyperpolarizations 
increase the rate of $\mathrm{Na}_{\mathrm{V}}$ channels recruitment from steady-state inactivation (Vandael et al., 2015; Guarina et al., 2018), while the recrutiment of different $\mathrm{Na}_{\mathrm{V}}$ channel isoform that characterized by a lower threshold of activation cannot be excluded.

Concerning the opposing effect that was observed in a minority of neurons, in which L-DOPA increased the spiking activity (Figure 6), variable responses have also been described in Substantia Nigra pars compacta $(\mathrm{SNc})$ neurons, using MEA recordings from midbrain slices (Berretta et al., 2010). In that case, neurons that fired at high rates $(>5 \mathrm{~Hz})$ were insensitive to DA, while low-firing neurons were either highly or weakly inhibited by DA. Furthermore, a fraction of lowrate spiking neurons were insensitive to DA, or excited by $\mathrm{DA}$, and a minority of neurons were potentiated by LDOPA. Under our experimental conditions, where midbrain neurons were cultured for weeks on the microarray, signals detection may occur from different DA subpopulations (Lammel et al., 2008; Liss and Roeper, 2010), either from non-DA neurons or from DA neurons of the nearby ventral tegmental area. Indeed, the excitatory effects of L-DOPA on nigral dopaminergic neurons have been previously described, and were featured as an "early" and a "late" phase of excitation (Guatteo et al., 2013).

Finally, regarding the fraction of neurons that were inhibited by L-DOPA and did not undergo relevant membrane potential hyperpolarization, several pathways may be responsible for this modulation, based on the involvement of $\mathrm{K}^{+}$channels other than GIRK (Yang et al., 2013), or $\mathrm{D}_{1}$-mediated signaling cascades (Surmeier et al., 2007).

\section{CONCLUSION}

Our data demonstrate that $\mu \mathrm{G}$-SCD-MEAs are highly reliable as multi-functional sensing multiarrays for long-term recordings of neuronal activity under variable pharmacological conditions. With respect to conventional approaches, the real-time measurements of quantal exocytosis and neuronal firing makes $\mu \mathrm{G}-\mathrm{SCD}-\mathrm{MEA}$ a promising biosensor for in vitro investigation of neuronal circuit properties as well

\section{REFERENCES}

Aghajanian, G. K., and Bunney, B. S. (1977). Dopamine “autoreceptors": pharmacological characterization by microiontophoretic single cell recording studies. Naunyn Schmiedebergs Arch. Pharmacol. 297, 1-7. doi: 10.1007/ BF00508803

Alcaide, M., Taylor, A., Fjorback, M., Zachar, V., and Pennisi, C. P. (2016). Boron-doped nanocrystalline diamond electrodes for neural interfaces: in vivo biocompatibility evaluation. Front. Neurosci. 10:87. doi: 10.3389/fnins.2016. 00087

Al-Hasani, R., Foster, J. D., Metaxas, A., Ledent, C., Hourani, S. M., Kitchen, I., et al. (2011). Increased desensitization of dopamine $D(2)$ receptor-mediated response in the ventral tegmental area in the absence of adenosine A(2A) receptors. Neuroscience 190, 103-111. doi: 10.1016/j.neuroscience.2011. 05.068

Allio, A., Calorio, C., Franchino, C., Gavello, D., Carbone, E., and Marcantoni, A. (2015). Bud extracts from Tilia tomentosa Moench inhibit hippocampal as a valid tool for studying mistuned neurotransmission in neurodegenerative disorders.

\section{AUTHOR CONTRIBUTIONS}

GT performed the experiments and analyzed acquired data. FP fabricated the sensors, performed the experiments, and manuscript preparation. $\mathrm{AB}$ fabricated the sensors. $\mathrm{BP}$ contributed to critically editing the manuscript. SDM contributed to critically editing the manuscript. AP made hardware and software of the 16-channel setup and revised the manuscript. PO contributed to the design for the diamond biosensor and to the preparation of the manuscript. AM contributed to experimental design and manuscript preparation. PC contributed to critically editing the manuscript. EC contributed to the interpretation of AP recordings and helped with a critical revision of the manuscript. VC contributed to planning the experimental design, manuscript writing, and overall revision.

\section{FUNDING}

This work was supported by the following projects: Project 2015FNWP34 (from Italian MIUR) to PC and VC and CSTO165284 (from Compagnia di San Paolo) to VC. DIACELL project (from National Institute of Nuclear Physics) to FP. MiRaDS project (from CRT Foundation), "Finanziamento expost di progetti di ricerca di Ateneo" (from CSP Foundation), "Departments of Excellence" (L. 232/2016) project (from Italian MIUR) to PO. Ion beam irradiation was performed at the AN2000 accelerator of the Legnaro National Laboratories of the Italian Institute of Nuclear Physics (INFN) within the "Dia.Fab." beamtime.

\section{ACKNOWLEDGMENTS}

We are grateful to Dr. Claudio Franchino for the preparation of cell cultures.

neuronal firing through GABAA and benzodiazepine receptors activation. J. Ethnopharmacol. 172, 288-296. doi: 10.1016/j.jep.2015.06.016

Amatore, C., Arbault, S., Lemaitre, F., and Verchier, Y. (2007). Comparison of apex and bottom secretion efficiency at chromaffin cells as measured by amperometry. Biophys. Chem. 127, 165-171. doi: 10.1016/j.bpc.2007.01.007

Battiato, A., Lorusso, M., Bernardi, E., Picollo, F., Bosia, F., Ugues, D., et al. (2016). Softening the ultra-stiff: controlled variation of Young's modulus in singlecrystal diamond by ion implantation. Acta Mater. 116, 95-103. doi: 10.1016/ j.actamat.2016.06.019

Bean, B. P. (2007). The action potential in mammalian central neurons. Nat. Rev. Neurosci. 8, 451-465. doi: 10.1038/nrn2148

Berretta, N., Bernardi, G., and Mercuri, N. B. (2010). Firing properties and functional connectivity of substantia nigra pars compacta neurones recorded with a multi-electrode array in vitro. J. Physiol. 588(Pt 10), 1719-1735. doi: 10.1113/jphysiol.2010.189415

Bigornia, L., Allen, C. N., Jan, C. R., Lyon, R. A., Titeler, M., and Schneider, A. S. (1990). D2 dopamine receptors modulate calcium channel currents and 
catecholamine secretion in bovine adrenal chromaffin cells. J. Pharmacol. Exp. Ther. 252, 586-592.

Bonnauron, M., Saada, S., Mer, C., Gesset, C., Williams, O. A., Rousseau, L., et al. (2008). Transparent diamond-on-glass micro-electrode arrays for exvivo neuronal study. Phys. Status Solidi (a) 205, 2126-2129. doi: 10.1002/pssa. 200879733

Carabelli, V., Marcantoni, A., Picollo, F., Battiato, A., Bernardi, E., Pasquarelli, A., et al. (2017). Planar diamond-based multiarrays to monitor neurotransmitter release and action potential firing: new perspectives in cellular neuroscience. ACS Chem. Neurosci. 8, 252-264. doi: 10.1021/acschemneuro.6b00328

Castagnola, E., Vahidi, N. W., Nimbalkar, S., Rudraraju, S., Thielk, M., Zucchini, E., et al. (2018). In vivo dopamine detection and single unit recordings using intracortical glassy carbon microelectrode arrays. MRS Adv. 3, 1629-1634. doi: 10.1557/adv.2018.98

Chen, T. K., Luo, G., and Ewing, A. G. (1994). Amperometric monitoring of stimulated catecholamine release from rat pheochromocytoma (PC12) cells at the zeptomole level. Anal. Chem. 66, 3031-3035. doi: 10.1021/ac00091a007

Cucchiaroni, M. L., Freestone, P. S., Berretta, N., Viscomi, M. T., Bisicchia, E., Okano, H., et al. (2011). Properties of dopaminergic neurons in organotypic mesencephalic-striatal co-cultures-evidence for a facilitatory effect of dopamine on the glutamatergic input mediated by alpha- 1 adrenergic receptors. Eur. J. Neurosci. 33, 1622-1636. doi: 10.1111/j.1460-9568.2011.07659.x

Dragicevic, E., Poetschke, C., Duda, J., Schlaudraff, F., Lammel, S., Schiemann, J., et al. (2014). Cav1.3 channels control D2-autoreceptor responses via NCS-1 in substantia nigra dopamine neurons. Brain 137(Pt 8), 2287-2302. doi: 10.1093/ brain/awu131

Dragicevic, E., Schiemann, J., and Liss, B. (2015). Dopamine midbrain neurons in health and Parkinson's disease: emerging roles of voltage-gated calcium channels and ATP-sensitive potassium channels. Neuroscience 284, 798-814. doi: 10.1016/j.neuroscience.2014.10.037

Duda, J., Potschke, C., and Liss, B. (2016). Converging roles of ion channels, calcium, metabolic stress, and activity pattern of Substantia nigra dopaminergic neurons in health and Parkinson's disease. J. Neurochem. 139(Suppl. 1), 156178. doi: $10.1111 /$ jnc. 13572

Fromherz, P. (1999). Extracellular recording with transistors and the distribution of ionic conductances in a cell membrane. Eur. Biophys. J. 28, 254-258. doi: 10.1007/s002490050206

Fromherz, P., Offenhausser, A., Vetter, T., and Weis, J. (1991). A neuron-silicon junction: a Retzius cell of the leech on an insulated-gate field-effect transistor. Science 252, 1290-1293. doi: 10.1126/science.1925540

Gavello, D., Calorio, C., Franchino, C., Cesano, F., Carabelli, V., Carbone, E., et al. (2018). Early alterations of hippocampal neuronal firing induced by Abeta42. Cereb. Cortex 28, 433-446. doi: 10.1093/cercor/bhw377

Gavello, D., Rojo-Ruiz, J., Marcantoni, A., Franchino, C., Carbone, E., and Carabelli, V. (2012). Leptin counteracts the hypoxia-induced inhibition of spontaneously firing hippocampal neurons: a microelectrode array study. PLoS One 7:e41530. doi: 10.1371/journal.pone.0041530

Ghiglieri, V., Calabrese, V., and Calabresi, P. (2018). Alpha-synuclein: from early synaptic dysfunction to neurodegeneration. Front. Neurol. 9:295. doi: 10.3389/ fneur.2018.00295

Gippius, A. A., Khmelnitskiy, R. A., Dravin, V. A., and Tkachenko, S. D. (1999). Formation and characterization of graphitized layers in ion-implanted diamond. Diamond Relat. Mater. 8, 1631-1634. doi: 10.1016/s0925-9635(99) 00047-3

Guarina, L., Calorio, C., Gavello, D., Moreva, E., Traina, P., Battiato, A., et al. (2018). Nanodiamonds-induced effects on neuronal firing of mouse hippocampal microcircuits. Sci. Rep. 8:2221. doi: 10.1038/s41598-01820528-5

Guatteo, E., Yee, A., McKearney, J., Cucchiaroni, M. L., Armogida, M., Berretta, N., et al. (2013). Dual effects of L-DOPA on nigral dopaminergic neurons. Exp. Neurol. 247, 582-594. doi: 10.1016/j.expneurol.2013. 02.009

Hafizi, S., Kruk, Z. L., and Stamford, J. A. (1990). Fast cyclic voltammetry: improved sensitivity to dopamine with extended oxidation scan limits. J. Neurosci. Methods 33, 41-49. doi: 10.1016/0165-0270(90)90080-Y

Hage, T. A., and Khaliq, Z. M. (2015). Tonic firing rate controls dendritic Ca2+ signaling and synaptic gain in substantia nigra dopamine neurons. J. Neurosci. 35, 5823-5836. doi: 10.1523/jneurosci.3904-14.2015
Heien, M. L., and Wightman, R. M. (2006). Phasic dopamine signaling during behavior, reward, and disease states. CNS Neurol. Disord. Drug Targets 5, 99-108. doi: 10.2174/187152706784111605

Henderson, B. J., Wall, T. R., Henley, B. M., Kim, C. H., Nichols, W. A., Moaddel, R., et al. (2016). Menthol alone upregulates midbrain nAChRs, alters nAChR subtype stoichiometry, alters dopamine neuron firing frequency, and prevents nicotine reward. J. Neurosci. 36, 2957-2974. doi: 10.1523/jneurosci. 4194- 15.2016

Hickey, D. P., Jones, K. S., and Elliman, R. G. (2009). Amorphization and graphitization of single-crystal diamond - A transmission electron microscopy study. Diamond Relat. Mater. 18, 1353-1359. doi: 10.1016/j.diamond.2009. 08.012

Hoffman, A., Bobrov, K., Fisgeer, B., Shechter, H., and Folman, M. (1996). Annealing of ion beam amorphized diamond surfaces studied by in situ electron spectroscopy. Diamond Relat. Mater. 5, 76-82. doi: 10.1016/0925-9635(96) 80008-2

Kawagoe, K. T., and Wightman, R. M. (1994). Characterization of amperometry for in vivo measurement of dopamine dynamics in the rat brain. Talanta 41, 865-874. doi: 10.1016/0039-9140(94)E0064-X

Khmelnitsky, R. A., Dravin, V. A., Tal, A. A., Zavedeev, E. V., Khomich, A. A., Khomich, A. V., et al. (2015). Damage accumulation in diamond during ion implantation. J. Mater. Res. 30, 1583-1592. doi: 10.1557/jmr.2015.21

Lacey, M. G., Mercuri, N. B., and North, R. A. (1987). Dopamine acts on D2 receptors to increase potassium conductance in neurones of the rat substantia nigra zona compacta. J. Physiol. 392, 397-416. doi: 10.1113/jphysiol.1987. sp016787

Lammel, S., Hetzel, A., Hackel, O., Jones, I., Liss, B., and Roeper, J. (2008). Unique properties of mesoprefrontal neurons within a dual mesocorticolimbic dopamine system. Neuron 57, 760-773. doi: 10.1016/j.neuron.2008. 01.022

Lin, Y., Trouillon, R., Svensson, M. I., Keighron, J. D., Cans, A. S., and Ewing, A. G. (2012). Carbon-ring microelectrode arrays for electrochemical imaging of single cell exocytosis: fabrication and characterization. Anal. Chem. 84, 2949-2954. doi: 10.1021/ac3000368

Liss, B., and Roeper, J. (2010). A new tool for your novelty centre. J. Physiol. 588(Pt 12), 2013. doi: 10.1113 /jphysiol.2010.192203

Marcantoni, A., Baldelli, P., Hernandez-Guijo, J. M., Comunanza, V., Carabelli, V., and Carbone, E. (2007). L-type calcium channels in adrenal chromaffin cells: role in pace-making and secretion. Cell Calcium 42, 397-408. doi: 10.1016/j. ceca.2007.04.015

Marcantoni, A., Raymond, E. F., Carbone, E., and Marie, H. (2014). Firing properties of entorhinal cortex neurons and early alterations in an Alzheimer's disease transgenic model. Pflugers Arch. 466, 1437-1450. doi: 10.1007/s00424013-1368-z

Margolis, E. B., Coker, A. R., Driscoll, J. R., Lemaitre, A. I., and Fields, H. L. (2010). Reliability in the identification of midbrain dopamine neurons. PLoS One 5:e15222. doi: 10.1371/journal.pone.0015222

Martinoia, S., Bonzano, L., Chiappalone, M., Tedesco, M., Marcoli, M., and Maura, G. (2005). In vitro cortical neuronal networks as a new high-sensitive system for biosensing applications. Biosens. Bioelectron. 20, 2071-2078. doi: 10.1016/j.bios.2004.09.012

Matsushita, N., Okada, H., Yasoshima, Y., Takahashi, K., Kiuchi, K., and Kobayashi, K. (2002). Dynamics of tyrosine hydroxylase promoter activity during midbrain dopaminergic neuron development. J. Neurochem. 82, 295304. doi: 10.1046/j.1471-4159.2002.00972.x

Mercuri, N. B., Calabresi, P., and Bernardi, G. (1990). Responses of rat substantia nigra compacta neurones to L-DOPA. Br. J. Pharmacol. 100, 257-260. doi: 10.1111/j.1476-5381.1990.tb15792.x

Mosharov, E. V., and Sulzer, D. (2005). Analysis of exocytotic events recorded by amperometry. Nat. Methods 2, 651-658. doi: 10.1038/nmeth782

Nistor, P. A., May, P. W., Tamagnini, F., Randall, A. D., and Caldwell, M. A. (2015). Long-term culture of pluripotent stem-cell-derived human neurons on diamond-A substrate for neurodegeneration research and therapy. Biomaterials 61, 139-149. doi: 10.1016/j.biomaterials.2015.04.050

Olivero, P., Amato, G., Bellotti, F., Borini, S., Lo Giudice, A., Picollo, F., et al. (2010). Direct fabrication and IV characterization of sub-surface conductive channels in diamond with $\mathrm{MeV}$ ion implantation. Eur. Phys. J. B 75, 127-132. doi: 10.1140/epjb/e2009-00427-5 
Patel, B. A., Luk, C. C., Leow, P. L., Lee, A. J., Zaidi, W., and Syed, N. I. (2013). A planar microelectrode array for simultaneous detection of electrically evoked dopamine release from distinct locations of a single isolated neuron. Analyst 138, 2833-2839. doi: 10.1039/c3an36770c

Patel, J. C., and Rice, M. E. (2013). Monitoring axonal and somatodendritic dopamine release using fast-scan cyclic voltammetry in brain slices. Methods Mol. Biol. 964, 243-273. doi: 10.1007/978-1-62703-251-3_15

Picconi, B., De Leonibus, E., and Calabresi, P. (2018). Synaptic plasticity and levodopa-induced dyskinesia: electrophysiological and structural abnormalities. J. Neural Transm (Vienna) 125, 1263-1271. doi: 10.1007/s00702-018-1864-6

Picollo, F., Battiato, A., Bernardi, E., Boarino, L., Enrico, E., Forneris, J., et al. (2015a). Realization of a diamond based high density multi electrode array by means of Deep Ion Beam Lithography. Nucl. Instrum. Methods Phys. Res. Sect. B Beam Interact. Mater. Atoms 348, 199-202. doi: 10.1016/j.nimb.2014.11.119

Picollo, F., Battiato, A., Carbone, E., Croin, L., Enrico, E., Forneris, J., et al. (2015b). Development and characterization of a diamond-insulated graphitic multi electrode array realized with ion beam lithography. Sensors (Basel) 15, 515-528. doi: 10.3390/s150100515

Picollo, F., Battiato, A., Bernardi, E., Marcantoni, A., Pasquarelli, A., Carbone, E., et al. (2016a). Microelectrode arrays of diamond-insulated graphitic channels for real-time detection of exocytotic events from cultured chromaffin cells and slices of adrenal glands. Anal. Chem. 88, 7493-7499. doi: 10.1021/acs.analchem. 5 b04449

Picollo, F., Battiato, A., Bernardi, E., Plaitano, M., Franchino, C., Gosso, S., et al. (2016b). All-carbon multi-electrode array for real-time in vitro measurements of oxidizable neurotransmitters. Sci. Rep. 6:20682. doi: 10.1038/srep 20682

Picollo, F., Gosso, S., Vittone, E., Pasquarelli, A., Carbone, E., Olivero, P., et al. (2013). A new diamond biosensor with integrated graphitic microchannels for detecting quantal exocytic events from chromaffin cells. Adv. Mater. 25, 4696-4700. doi: 10.1002/adma.201300710

Picollo, F., Monticone, D. G., Olivero, P., Fairchild, B. A., Rubanov, S., Prawer, S., et al. (2012). Fabrication and electrical characterization of three-dimensional graphitic microchannels in single crystal diamond. N. J. Phys. 14:053011. doi: 10.1088/1367-2630/14/5/053011

Piret, G., Hebert, C., Mazellier, J.-P., Rousseau, L., Scorsone, E., Cottance, M., et al. (2015). 3D-nanostructured boron-doped diamond for microelectrode array neural interfacing. Biomaterials 53, 173-183. doi: 10.1016/j.biomaterials.2015. 02.021

Pothos, E. N. (2002). Regulation of dopamine quantal size in midbrain and hippocampal neurons. Behav. Brain Res. 130, 203-207. doi: 10.1016/S01664328(01)00419-3

Pothos, E. N., Davila, V., and Sulzer, D. (1998). Presynaptic recording of quanta from midbrain dopamine neurons and modulation of the quantal size. J. Neurosci. 18, 4106-4118. doi: 10.1523/JNEUROSCI.18-11-04106.1998

Pruszak, J., Just, L., Isacson, O., and Nikkhah, G. (2009). Isolation and culture of ventral mesencephalic precursor cells and dopaminergic neurons from rodent brains. Curr. Protoc. Stem. Cell Biol. Chapter 2:Unit 2D.5. doi: 10.1002/ 9780470151808.sc02d05s11

Ramayya, A. G., Zaghloul, K. A., Weidemann, C. T., Baltuch, G. H., and Kahana, M. J. (2014). Electrophysiological evidence for functionally distinct neuronal populations in the human substantia nigra. Front. Hum. Neurosci. 8:655. doi: 10.3389/fnhum.2014.00655

Rice, M. E., and Patel, J. C. (2015). Somatodendritic dopamine release: recent mechanistic insights. Philos. Trans. R. Soc. Lond. B Biol. Sci. 370:1672. doi: 10.1098/rstb.2014.0185

Sawamoto, K., Nakao, N., Kobayashi, K., Matsushita, N., Takahashi, H., Kakishita, K., et al. (2001). Visualization, direct isolation, and transplantation of midbrain dopaminergic neurons. Proc. Natl. Acad. Sci. U.S.A. 98, 6423-6428. doi: 10.1073/pnas.111152398

Schirinzi, T., Madeo, G., Martella, G., Maltese, M., Picconi, B., Calabresi, P., et al. (2016). Early synaptic dysfunction in Parkinson's disease: insights from animal models. Mov. Disord. 31, 802-813. doi: 10.1002/mds. 26620
Staal, R. G., Mosharov, E. V., and Sulzer, D. (2004). Dopamine neurons release transmitter via a flickering fusion pore. Nat. Neurosci. 7, 341-346. doi: 10.1038/ nn1205

Sulzer, D., Cragg, S. J., and Rice, M. E. (2016). Striatal dopamine neurotransmission: regulation of release and uptake. Basal Ganglia 6, 123-148. doi: 10.1016/j.baga.2016.02.001

Surmeier, D. J., Ding, J., Day, M., Wang, Z., and Shen, W. (2007). D1 and D2 dopamine-receptor modulation of striatal glutamatergic signaling in striatal medium spiny neurons. Trends Neurosci. 30, 228-235. doi: 10.1016/j.tins.2007. 03.008

Suzuki, A., Ivandini, T. A., Yoshimi, K., Fujishima, A., Oyama, G., Nakazato, T., et al. (2007). Fabrication, characterization, and application of boron-doped diamond microelectrodes for in vivo dopamine detection. Anal. Chem. 79, 8608-8615. doi: 10.1021/ac071519h

Suzuki, I., Fukuda, M., Shirakawa, K., Jiko, H., and Gotoh, M. (2013). Carbon nanotube multi-electrode array chips for noninvasive real-time measurement of dopamine, action potentials, and postsynaptic potentials. Biosens. Bioelectron. 49, 270-275. doi: 10.1016/j.bios.2013.05.023

Tang, L., Tsai, C., Gerberich, W. W., Kruckeberg, L., and Kania, D. R. (1995). Biocompatibility of chemical-vapour-deposited diamond. Biomaterials 16, 483488. doi: 10.1016/0142-9612(95)98822-V

Trouillon, R., and Ewing, A. G. (2014). Actin controls the vesicular fraction of dopamine released during extended kiss and run exocytosis. ACS Chem. Biol. 9, 812-820. doi: 10.1021/cb400665f

Vandael, D. H., Marcantoni, A., Mahapatra, S., Caro, A., Ruth, P., Zuccotti, A., et al. (2010). $\mathrm{Ca}(\mathrm{v}) 1.3$ and $\mathrm{BK}$ channels for timing and regulating cell firing. Mol. Neurobiol. 42, 185-198. doi: 10.1007/s12035-010-8151-3

Vandael, D. H., Ottaviani, M. M., Legros, C., Lefort, C., Guerineau, N. C., Allio, A., et al. (2015). Reduced availability of voltage-gated sodium channels by depolarization or blockade by tetrodotoxin boosts burst firing and catecholamine release in mouse chromaffin cells. J. Physiol. 593, 905-927. doi: 10.1113/jphysiol.2014.283374

Vandael, D. H., Zuccotti, A., Striessnig, J., and Carbone, E. (2012). Ca(V)1.3-driven SK channel activation regulates pacemaking and spike frequency adaptation in mouse chromaffin cells. J. Neurosci. 32, 16345-16359. doi: 10.1523/jneurosci. 3715-12.2012

Waelti, P., Dickinson, A., and Schultz, W. (2001). Dopamine responses comply with basic assumptions of formal learning theory. Nature 412, 43-48. doi: $10.1038 / 35083500$

Wu, W., and Fahy, S. (1994). Molecular-dynamics study of single-atom radiation damage in diamond. Phys. Rev. B 49, 3030-3035. doi: 10.1103/PhysRevB.49. 3030

Yang, J., Ye, M., Tian, C., Yang, M., Wang, Y., and Shu, Y. (2013). Dopaminergic modulation of axonal potassium channels and action potential waveform in pyramidal neurons of prefrontal cortex. J. Physiol. 591, 3233-3251. doi: 10.1113/ jphysiol.2013.251058

Yasumoto, F., Negishi, T., Ishii, Y., Kyuwa, S., Kuroda, Y., and Yoshikawa, Y. (2004). Endogenous dopamine maintains synchronous oscillation of intracellular calcium in primary cultured-mouse midbrain neurons. Cell Mol. Neurobiol. 24, 51-61. doi: 10.1023/B:CEMN.0000012724.79184.b6

Ziegler, J. F., Ziegler, M. D., and Biersack, J. P. (2010). SRIM - The stopping and range of ions in matter. Nucl. Instrum. Methods Phys. Res. Sect. B Beam Interact. Mater. Atoms 268, 1818-1823. doi: 10.1016/j.nimb.2010.02.091

Conflict of Interest Statement: The authors declare that the research was conducted in the absence of any commercial or financial relationships that could be construed as a potential conflict of interest.

Copyright (c) 2019 Tomagra, Picollo, Battiato, Picconi, De Marchis, Pasquarelli, Olivero, Marcantoni, Calabresi, Carbone and Carabelli. This is an open-access article distributed under the terms of the Creative Commons Attribution License (CC BY). The use, distribution or reproduction in other forums is permitted, provided the original author(s) and the copyright owner(s) are credited and that the original publication in this journal is cited, in accordance with accepted academic practice. No use, distribution or reproduction is permitted which does not comply with these terms. 